\title{
Genome-wide identification, molecular evolution, and expression analysis of auxin response factor (ARF) gene family in Brachypodium distachyon L
}

Nannan Liư ${ }^{\dagger}$, Liwei Dong ${ }^{\dagger}$, Xiong Deng ${ }^{\dagger}$, Dongmiao Liu, Yue Liu, Mengfei Li, Yingkao Hu ${ }^{*}$ and Yueming Yan*

\begin{abstract}
Background: The auxin response factor (ARF) gene family is involved in plant development and hormone regulation. Although the ARF gene family has been studied in some plant species, its structural features, molecular evolution, and expression profiling in Brachypodium distachyon L. are still not clear.

Results: Genome-wide analysis identified 19 ARF genes in B. distachyon. A phylogenetic tree constructed with 182 ARF genes from seven plant species revealed three different clades, and the ARF genes from within a clade exhibited structural conservation, although certain divergences occurred in different clades. The branch-site model identified some sites where positive selection may have occurred, and functional divergence analysis found more Type II divergence sites than Type I. In particular, both positive selection and functional divergence may have occurred in 241H, 243G, $244 \mathrm{~L}, 310 \mathrm{~T}, 340 \mathrm{G}$ and $355 \mathrm{~T}$. Subcellular localization prediction and experimental verification indicated that BdARF proteins were present in the nucleus. Transcript expression analysis revealed that $B d A R F s$ were mainly expressed in the leaf and root tips, stems, and developing seeds. Some BdARF genes exhibited significantly upregulated expression under various abiotic stressors. Particularly, BdARF4 and BdARF8 were significantly upregulated in response to abiotic stress factors such as salicylic acid and heavy metals.

Conclusion: The ARF gene family in B. distachyon was highly conserved. Several important amino acid sites were identified where positive selection and functional divergence occurred, and they may play important roles in functional differentiation. BdARF genes had clear tissue and organ expression preference and were involved in abiotic stress response, suggesting their roles in plant growth and stress resistance.
\end{abstract}

Keywords: Abiotic stress, ARF genes, Brachypodium distachyon, Phylogenetic relationships, qRT-PCR

\section{Background}

Auxin plays an important role in plant growth and development, including shoot elongation, lateral root formation, vascular tissue differentiation, apical margin patterning, and response to environmental stimuli [1]. The auxin gene family is involved in plant stress response, and includes Aux/IAA, Small Auxin Up RNA (SAUR), and Gretchen Hagen $3(G H 3)[2,3]$. Auxin response factors (ARFs), a critical family of transcription factors in the auxin-mediated pathway, are involved in hormone

\footnotetext{
* Correspondence: yingkaohu@cnu.edu.cn; yanym@cnu.edu.cn

${ }^{\dagger}$ Nannan Liu, Liwei Dong and Xiong Deng contributed equally to this work. College of Life Science, Capital Normal University, Beijing 100048, China
}

regulation and plant development [4-6]. They specifically bind the auxin response element (AuxREs) $(5$ ' $\rightarrow$ 3'TGTC $\mathrm{TC})$ in the promoter region of auxin response genes to regulate gene transcription $[1,7]$.

ARFs contain three unique domains: a conservative N-terminal DNA-binding domain (DBD), a variable middle transcriptional regulatory region (MR) that functions as an activation domain (AD) or repression domain (RD), and a C-terminal dimerization domain (CTD) $[8,9]$. The main function of a DBD, which contains the B3 and auxin_resp domains, is binding the AuxREs of auxin response genes [10]. The type of amino acid in the MR determines whether gene transcription is 
activated or repressed. An AD is generally rich in glutamine $(\mathrm{Q})$, serine $(\mathrm{S})$, and leucine $(\mathrm{L})$ residues, while a $R D$ is rich in proline $(P)$, serine $(S)$, threonine $(T)$, and glycine $(\mathrm{G})$ residues $[7,9]$. A CTD, similar to the PB1 domain of the Aux/IAA protein, includes motifs III and IV that involve protein-protein interactions and mediate the homodimerization of ARFs or the heterodimerization of ARF and Aux/IAA [7, 10, 11]. Plant-specific responses to auxin occur generally through the interaction of ARF and Aux/IAA proteins [12]. When the concentration of auxin is low, the heterodimerization of Aux/ IAA and ARF inhibits the transcription activity of ARF, thereby preventing the transcription of related genes. Nevertheless, when the auxin concentration reaches a certain level, the ubiquitin ligase $\mathrm{SCF}^{\mathrm{TIR} 1 / \mathrm{AFB}}$ subunit ubiquitinates Aux/IAA and degrades it via the $26 \mathrm{~S}$ proteasome pathway, weakening the inhibitory effect of Aux/IAA on ARF [7, 8].

Since the identification of ARF genes in Arabidopsis thaliana [13], ARFs have been found in about 16 plant species. And their structure, evolution, and expression profiling have been widely investigated in these plants such as Arabidopsis [14], rice [15], and maize [16]. ARFs play an important role in plant growth and development. For example, AtARF2 can regulate floral shedding [17], leaf senescence [18], and seed size [19]; AtARF3 deficiency causes abnormal floral meristems and reproductive organs [20]; AtARF5 is associated with the formation of vascular bundles and hypocotyls [21]; ARF6 and ARF8 coordinate the transition from immature to mature, fertile flowers [22]; and AtARF7 and AtARF19 regulate lateral root formation by activating the $L B D / A S L$ gene [23]. In the tomato plant (Solanum lycopersicum), ARF genes may influence flower and fruit development [24], and SlARF4 plays a role in sugar metabolism during fruit development [25]. In rice, OsARF12 plays a role in regulating phosphate homeostasis [26]. Notably, the $A R F$ gene family participates in the response of plants to abiotic stressors [27-30]. For example, many ARF genes in Sorghum bicolor exhibit significant expression changes in response to salt and drought stress [29]. Some water stress-responsive GmARFs in soybean (Glycine max) have been identified using quantitative real-time polymerase chain reaction (qRT-PCR) and microarray data [30].

Brachypodium distachyon L. $(2 \mathrm{n}=10)$, the first sequencing member in Pooideae [31], is an ideal model plant to study cereals [32]. It has simple growth requirements [32, 33], a small genome, diploid accessions (272 Mb), self-fertility, a short generation time, a small stature but large seeds, and is more closely related to Triticeae crops than rice [34]. Although some studies have focused on the $A R F$ gene family [14-16], the structural characterization, molecular evolution, expression profiling, and functional properties of the $B$. distachyon $A R F$ family are still not clear. We completed the first comprehensive genome-wide analysis of the ARF gene family in $B$. distachyon, and our results provide new insights into the structure, evolution, and function of the plant's $A R F$ family.

\section{Results}

Genome-wide identification of ARFs in B. distachyon and other plant species

The 23 and 25 known ARF amino acid sequences from rice and Arabidopsis, respectively, were obtained from the RGAP and TAIR databases. These sequences were used as queries for searches in the Phytozome database. If the $E$-value $\leq 1 \mathrm{e}-5$ of the sequence obtained by BLAST, it is regarded as a candidate sequence. The BLASTP search results were further examined using the online tools SMART [35] and Pfam [36] to confirm the presence of the conserved B3 and Auxin_resp domains, and any redundant or partial sequences were manually removed. The remaining sequences satisfied the amino acid sequences starting from $\mathrm{M}$ without $\mathrm{N}$ in the CDS and had the whole gene sequences. Ultimately, a total of 19 ARF protein family members from $B$. distachyon and 163 from six other plant species were identified: 20 from Oryza sativa, 63 from Triticum aestivum, 18 from Setaria italic, 25 from Zea mays, 21 from Sorghum bicolor, and 16 from Arabidopsis thaliana. The basic information containing gene name, locus, protein length, intron number, predicted isoelectric point $(p I)$, and molecular weight $(\mathrm{MW})$ are shown in Additional file 1: Table S1, and their conserved motifs identified by SMART and Pfam are listed in Additional file 1: Table S2. Generally, ARFs encode proteins with 513-1175 amino acids (AA), predicted isoelectric points $(p I)$ from 5.45 to 9.18 , and molecular weights (MW) between 63.74 and $130.93 \mathrm{kDa}$.

\section{Chromosome and subcellular localization of BdARFs}

Using the MapInspect program, all $19 A R F$ genes from $B$. distachyon were mapped to five different chromosomes (Fig. 1): two genes were on chromosome 01 (BdARF2:Bradilg32547 and BdARF19: Bradi1g33160), six were on chromosome 02 (BdARF10: Bradi2g59480; BdARF11: Bradi2g16610; BdARF12: Bradi2g50120; BdARF13: Bradi2g46190; BdARF14: Bradi2g08120; and BdARF15: Bradi2g19867), four on chromosome 03 (BdARF3: Bradi3g04920; BdARF6: Bradi3g45880; BdARF16: Bradi3g28950 and BdARF17: Bradi3g49320), three on chromosome 04 (BdARF1: Bradi4g01730; BdARF7: Bradi4g17410 and BdARF9: Bradi4g07470), and four on chromosome 05 (BdARF4: Bradi5g25767; BdARF5: Bradi5g25157; BdARF8: Bradi5g10950 and BdARF18: Bradi5g15904). 


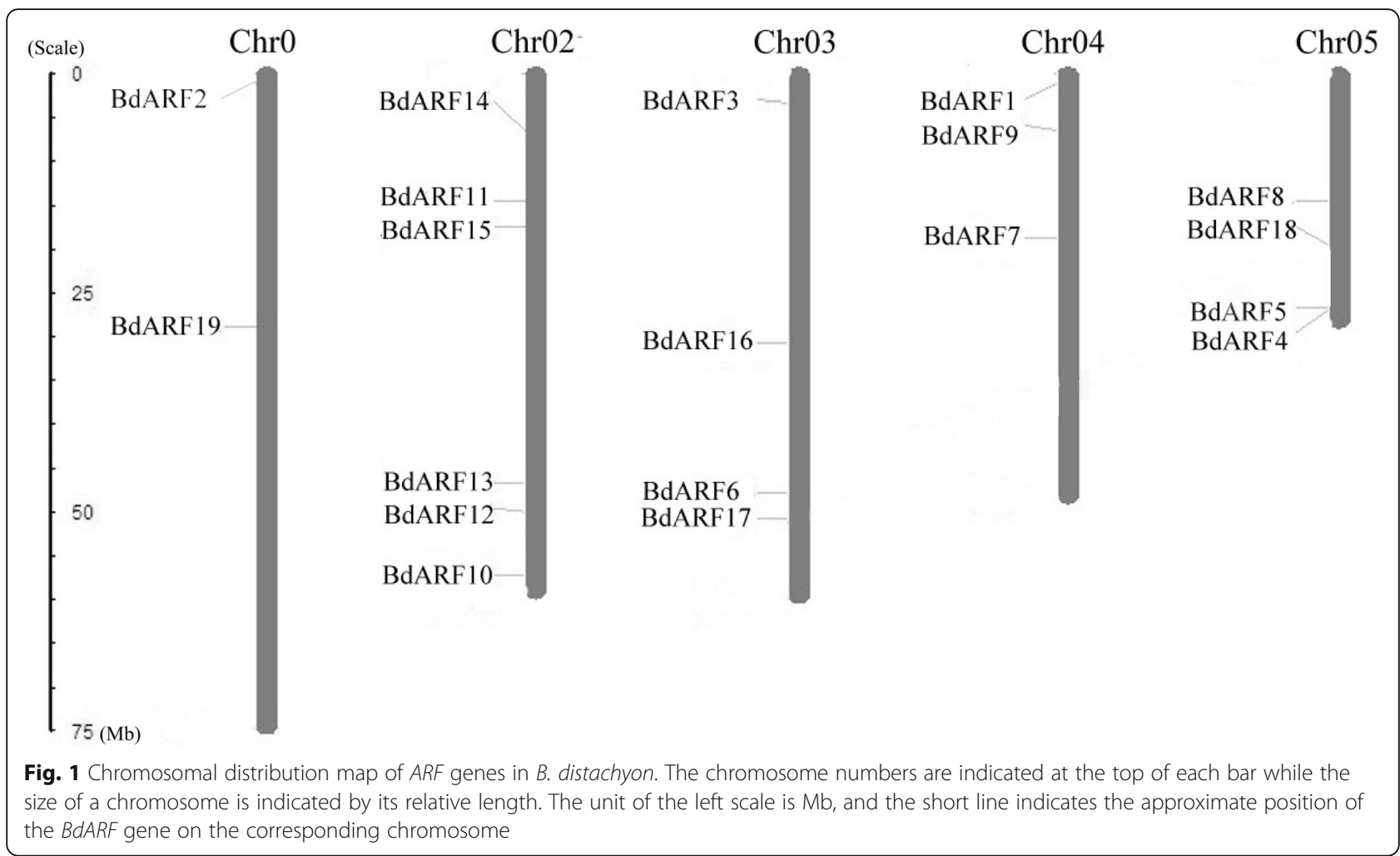

The location of proteins encoded by the 19 ARFs in $B$. distachyon were all predicted to be located in the nucleus by the five different software programs. To verify these subcellular localization predictions, five $A R F$ genes were selected to carry out transient expression with green fluorescent protein (GFP) fusion proteins in Arabidopsis suspension culture cells. Confocal laser microscopy was used to perform microexamination. These proteins (BdARF1, BdARF4, BdARF5, BdARF8, and BdARF16) were used to establish recombinant plasmids (BdARF1::GFP, BdARF4::GFP, BdARF5::GFP, BdARF8::GFP, and $B d A R F 16:: G F P)$ with the $35 \mathrm{~S}$ promoter. Additional file 1: Table S3 summarizes the primers used. The green fluorescent signals of the five GFP fusion proteins were particularly strong in the nucleus (Fig. 2) and consistent with the predicted results.

\section{Phylogeny and molecular characterization of ARFs}

Multiple sequence alignments of 182 ARF proteins were performed using the Multiple Sequence Comparison by Log-Expectation (MUSCLE) program [37, 38], followed by construction of an unrooted phylogenetic tree using the Markov Chain Monte Carlo (MCMC) method based on Bayesian inference [39]. The 182 ARF proteins were divided into three clades by combining later topology and structure similarity analysis: clade I (including clades Ia and Ib), clade II, and clade III (Fig. 3). Clade Ib was the largest branch with $58 A R F$ gene members, followed by clade Ia (51 members), clade III (39 members), and clade II (34 members). The phylogenetic tree showed that $A R F$ genes from monocotyledonous plants such as $B$. distachyon were uniformly distributed in each clade, while those from the dicotyledonous Arabidopsis were mainly present in clade Ia.

The exon-intron structures of $A R F$ gene family from $B$. distachyon and the other six plant species were analyzed by submitting $A R F$ coding sequences (CDSs) and their corresponding gene sequences to Gene Structure Display Server (GSDS) [40]. There were no significant differences in the number of exons among members of the same clade, but noteworthy differences existed among different clades, especially between clade III and other clades (Additional file 2: Figure S1). Clade Ia, clade Ib, and clade II had 12-15 exons, 12-16 exons, and 912 exons, respectively. In clade III, all members had 2-5 exons, except for $S b A R F 1$ with 14 exons.

The motif detection software MEME (Multiple Em for Motif Elicitation) [41] was used to perform motif analysis of the ARF protein sequences. A total of 10 conserved motifs were detected from 182 ARFs. The orders and numbers of motifs in a single ARF were shown in Additional file 3: Figure S2, and the sequence composition of each motif was shown in Additional file 4: Figure S3. The number of motifs contained in ARFs generally ranged from 8 to 10 . According to the results of the motif detection, the distribution and position of the 


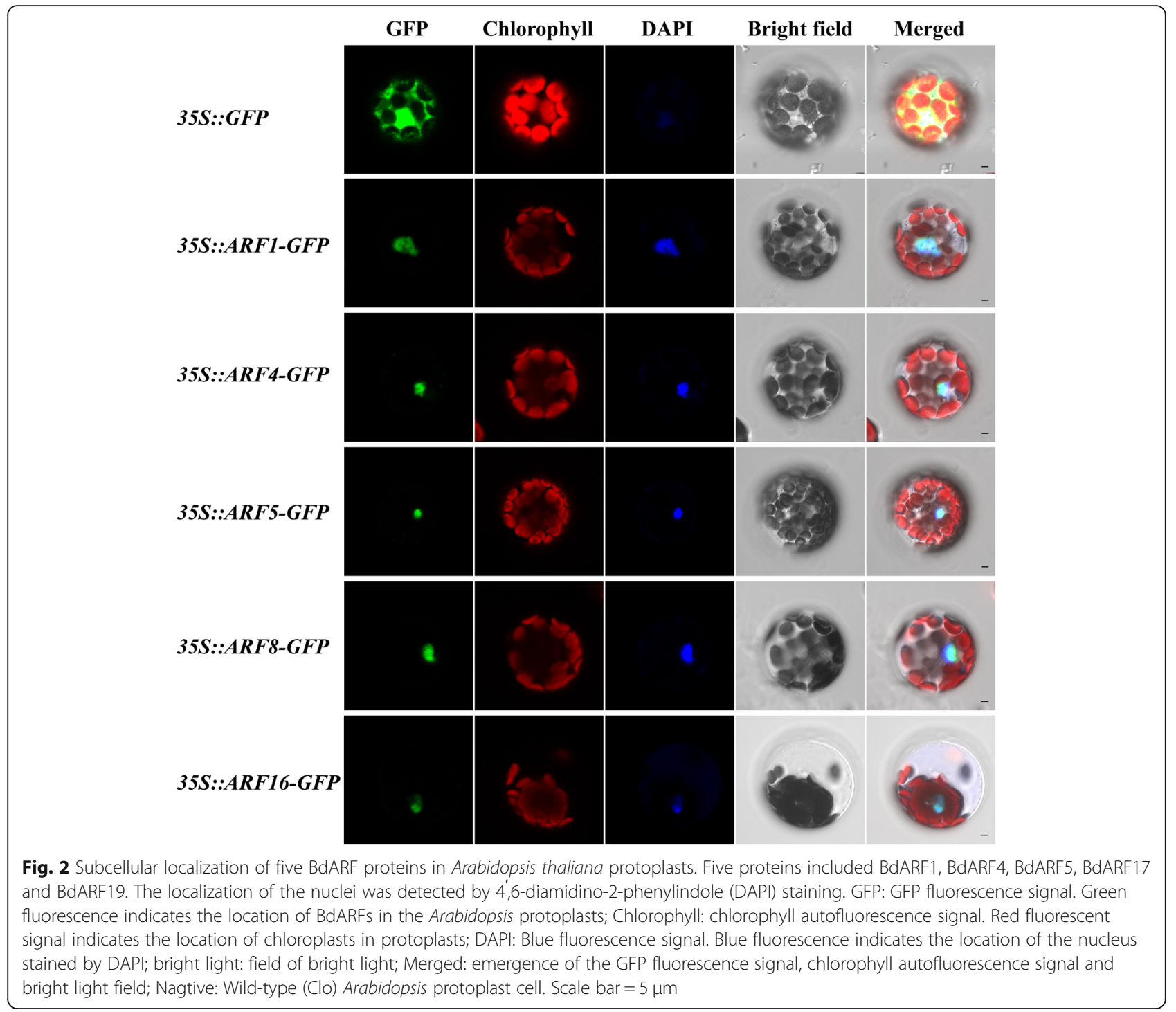

motifs were relatively conservative among the internal members of the clade. Interestingly, almost all members of clade II had 8 motifs, significantly different from other clades with $10-11$ motifs.

\section{Functional divergence and adaptive selection}

To explore whether the amino acid substitutions lead to functional divergence, the Type I and II functional divergences of the gene cluster in $A R F$ family were estimated using the DIVERGE v2.0 program [42, 43] (Table 1). The results revealed that the Type I functional divergence coefficient $(\theta \mathrm{I})$ between any two clades of ARF protein ranged from 0.209 to 0.733 , which was significantly greater than 0 . The LRT value reached a significant difference $(p<0.5)$, indicating the possible presence of Type I divergence sites during the evolution between the clades of plant ARF proteins. Similarly, the Type II functional divergence coefficient $(\theta \mathrm{II})$ ranged from -0.161 to
0.113 , which is also significantly greater than 0 , indicating that Type II functional divergence sites may be also present.

In accordance with Yang et al. [44], the posterior probability $(\mathrm{Qk})$ of divergence for each amino acid site was calculated to identify key sites related to functional divergence between every two clades. Large $\mathrm{Qk}$ values indicate a high probability of functional divergence between two clades [42]. Type I and II functional divergence residues with $\mathrm{Qk} \leq 0.95$ were excluded to reduce false positives. The results revealed that Type I and II functional divergence sites existed between every two clades, and variable numbers of Type I functional divergence sites (ds) were found between pairs of clades: clade Ia and Ib $(0 \mathrm{ds})$, Ia and II ( $8 \mathrm{ds})$, Ia and III (12 ds), Ib and II ( $2 \mathrm{ds})$, Ib and III ( $8 \mathrm{ds})$, and II and III ( $3 \mathrm{ds})$. In contrast, Type II sites were much more common than Type I sites (Table 1). The specific Type I and II 


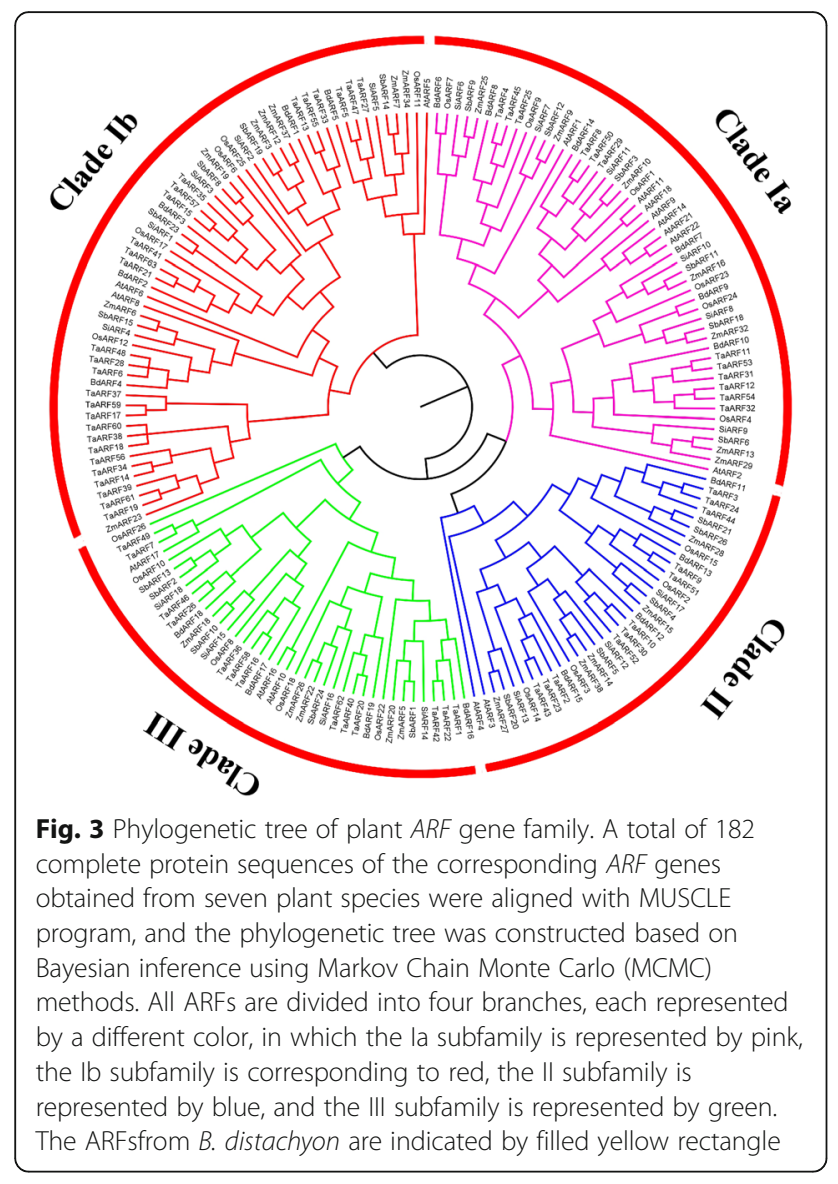

functional divergence sites are shown in Additional file 1: Table S4. Particularly, 8 amino acid sites underwent both the Type I and II functional divergence, indicating that their evolutionary rates and physicochemical properties were altered (Additional file 5: Figure S4).

To assume variable selective pressure among sites, a site-specific model was applied to the $A R F$ gene families in the seven selected plant species. Two pairs of models, M0 (one scale) and M3 (discrete), as well as M7 (beta) and M8 (beta and $\omega$ ) [45], were applied in this analysis (Additional file 1: Table S5). No amino acid sites were identified as being under positive selection, indicating that the $A R F$ gene family is not under selective pressure. The branch site model of $A R F$ gene family was further analyzed using site-specific analysis (Table 2). Seven positive selection sites in clade Ia were identified, including four critical positive selection sites (340G, $355 \mathrm{~T}$, $356 \mathrm{~T}$ and 358P, $p<0.01$ ). Meanwhile, 44 and 20 positive selection sites were present in clade II and clade III respectively, including 34 critical sites in clade II (232S, $250 \mathrm{H}, 259 \mathrm{~T}, p<0.05 ; 230 \mathrm{M}, 238 \mathrm{D}, 239 \mathrm{~S}, 240 \mathrm{M}, 241 \mathrm{H}$, 243G, 244 L, 246A, 247A, $255 \mathrm{~N}, 275 \mathrm{~L}, 276 \mathrm{~A}, 279 \mathrm{~V}$, $282 \mathrm{~V}, 287 \mathrm{~V}, 289 \mathrm{~V}, 295 \mathrm{M}, 308 \mathrm{M}, 310 \mathrm{~T}, 312 \mathrm{~T}, 314 \mathrm{I}$, 337S, $338 \mathrm{~T}, 340 \mathrm{G}, 343 \mathrm{Q}, 344 \mathrm{P}, 345 \mathrm{R}, 353 \mathrm{P}, 354 \mathrm{~L}, 358 \mathrm{P}$, and 371P, $p<0.01)$ and 12 critical sites in clade III (253A, 254 T, 286R, $p<0.05$; 204D, $230 \mathrm{M}, 231 \mathrm{P}, 232 \mathrm{~S}$, 233S, 236S, 237S, 246A, and 144G, $p<0.01$ ). Interestingly, clade Ib had no positive selection sites, implying that clade is under neutral or negative selection, while clades Ia, II and III may undergo strong positive selection. In particular, six sites $(241 \mathrm{H}, 243 \mathrm{G}, 244 \mathrm{~L}, 310 \mathrm{~T}$, $340 \mathrm{G}$ and $355 \mathrm{~T}$ ) experienced two types of functional divergences and positive selection pressure (Additional file 5: Figure S4).

\section{Promoter analysis of $A R F$ gene family}

Promoter regions contain cis-acting elements that regulate the expression of genes. The cis-acting elements in the $1500 \mathrm{bp}$ region upstream of the $A R F$ gene family were investigated by PlantCARE online tool [46]. In total, seven types of elements were identified: hormone responsive, environmental stress related, promoter related, site binding related, light responsive, developmental related elements, and others. Among them, photoperiod, developmental regulation, hormonal response, and environmental response were the key physiological processes closely related to the regulatory elements (Additional file 1: Table S6).

We analyzed the hormone responsive elements present in ARF gene family of $B$. distachyon, including P-box [47], GARE-motif [48], TCA-element [49], ABRE [50], TGAC G-motif, and CGTCA-motif. Among them, ABRE, TGAC G-motif, and CGTCA-motif were abundant, and the

Table 1 Functional divergence between clades of the ARF gene family

\begin{tabular}{|c|c|c|c|c|c|c|}
\hline \multirow[t]{2}{*}{ Group1 } & \multirow[t]{2}{*}{ Group2 } & \multicolumn{3}{|l|}{ Type I } & \multicolumn{2}{|l|}{ Type II } \\
\hline & & $\theta \mathrm{\theta l} \pm$ s.e. & LRT & $Q k>0.95$ & $\overline{\theta \|} \pm$ s.e. & $Q k>0.95$ \\
\hline la & $\mathrm{lb}$ & $0.209 \pm 0.075$ & $7.078931^{* *}$ & 0 & $-0.161 \pm 0.189$ & 0 \\
\hline la & ॥ & $0.422 \pm 0.049$ & $64.383411^{* *}$ & 8 & $0.041 \pm 0.191$ & 6 \\
\hline la & III & $0.631 \pm 0.049$ & $109.075555^{* *}$ & 12 & $0.081 \pm 0.227$ & 41 \\
\hline Ib & $\|$ & $0.612 \pm 0.073$ & $54.760541^{* *}$ & 2 & $-0.048 \pm 0.181$ & 3 \\
\hline $\mathrm{lb}$ & III & $0.733 \pm 0.071$ & $69.986229 * *$ & 8 & $0.113 \pm 0.211$ & 27 \\
\hline$\|$ & III & $0.485 \pm 0.070$ & $46.482589^{* *}$ & 3 & $-0.055 \pm 0.251$ & 15 \\
\hline
\end{tabular}

Note: $\theta$ I and $\theta l l$, the coefficients of Type-I and Type-II functional divergence; LRT, Likelihood Ratio Statistic, ${ }^{*}$ and ** representative $p<0.05$ and $p<0.01$, respectively; Qk, posterior probability 
Table 2 Parameters estimation and likelihood ratio tests of ARF genes for the branch-site models

\begin{tabular}{|c|c|c|c|c|c|}
\hline Clade & Model & $n p^{a}$ & $\operatorname{lnL}$ & $2 \Delta \operatorname{lnL}$ & Positive selected sites $^{b}$ \\
\hline \multirow[t]{2}{*}{ la } & $\begin{array}{l}\text { Model A- } \\
\text { null }\end{array}$ & 365 & $-30,653.840481$ & & Not allowed \\
\hline & Model A & 366 & $-30,653.840481$ & 0 & 169D, $339 \mathrm{~A}, 340 \mathrm{G}^{* *}, 355 \mathrm{~T}^{* *}, 356 \mathrm{~T}^{* *}, 358 \mathrm{P}^{* *}, 360 \mathrm{Y}$ \\
\hline \multirow[t]{2}{*}{ lb } & $\begin{array}{l}\text { Model A- } \\
\text { null }\end{array}$ & 365 & $-30,683.021342$ & & Not allowed \\
\hline & Model A & 366 & $-30,683.021342$ & 0 & None \\
\hline \multirow[t]{2}{*}{$\|$} & $\begin{array}{l}\text { Model A- } \\
\text { null }\end{array}$ & 365 & $-30,601.447106$ & & Not allowed \\
\hline & Model A & 366 & $-30,601.447106$ & 0 & $\begin{array}{l}229 \mathrm{I}, 230 \mathrm{M}^{* *}, 231 \mathrm{P}, 232 \mathrm{~S}^{*}, 236 \mathrm{~S}, \\
238 \mathrm{D}^{* *}, 239 \mathrm{~S}^{* *}, 240 \mathrm{M}^{* *}, 241 \mathrm{H}^{* *}, \\
243 \mathrm{G}^{* *}, 244 \mathrm{~L}^{* *}, 246 \mathrm{~A}^{* *}, 247 \mathrm{~A}^{* *}, \\
250 \mathrm{H}^{*}, 252 \mathrm{~A}, 255 \mathrm{~N}^{* *}, 259 \mathrm{~T}^{*}, 266 \mathrm{~S}, \\
273 \mathrm{I}, 275 \mathrm{~L}^{* *}, 276 \mathrm{~A}^{* *}, 279 \mathrm{~V}^{* * *}, \\
281 \mathrm{~S}, 282 \mathrm{~V}^{* *}, 283 \mathrm{Y}, 287 \mathrm{~V}^{* *}, \\
289 \mathrm{~V}^{* *}, 291 \mathrm{M}, 295 \mathrm{M}^{* *}, 297 \mathrm{~F}_{,} \\
308 \mathrm{M}^{* *}, 310 \mathrm{~T}^{* *}, 312 \mathrm{~T}^{*}, 314 \mathrm{I}^{* *}, \\
337 \mathrm{~S}^{* *}, 338 \mathrm{~T}^{* *}, 340 \mathrm{G}^{* *}, 343 \mathrm{Q}^{*}, \\
344 \mathrm{P}^{* *}, 345 \mathrm{R}^{*}, 353 \mathrm{P}^{*}, 354 \mathrm{~L}^{* *}, \\
358 \mathrm{P}^{* *}, 371 \mathrm{P}^{* *}\end{array}$ \\
\hline \multirow[t]{2}{*}{ III } & $\begin{array}{l}\text { Model A- } \\
\text { null }\end{array}$ & 365 & $-30,624.183120$ & & Not allowed \\
\hline & Model A & 366 & $-30,624.183120$ & 0 & $\begin{array}{l}193 \mathrm{~V}, 204 \mathrm{D}^{* *}, 213 \mathrm{~N}, 228 \mathrm{~T}, 230 \mathrm{M}^{* *}, 231 \mathrm{P}^{* *}, 232 \mathrm{~S}^{* *}, 233 \mathrm{~S}^{* *}, 236 \mathrm{~S}^{* *}, 237 \mathrm{~S}^{* *}, 241 \mathrm{H}, 246 \mathrm{~A}^{* *}, \\
250 \mathrm{H}, \\
698 \mathrm{~A}, 700 \mathrm{~A}^{*}, 701 \mathrm{~T}^{*}, 745 \mathrm{Y}, 749 \mathrm{R}^{*}, \\
752 \mathrm{~V}, 832 \mathrm{G}^{* *}\end{array}$ \\
\hline
\end{tabular}

Note: $p<0.05$ and $p<0.01$ were marked by* and ${ }^{* *}$, respectively. All sites are located on reference amino acid sequence BdARF1 according to the multiple sequence alignment result. Sites are highlighted in red subjected to functional divergence and positive selection

average copy numbers were $2.737,1.789$, and 1.789 , respectively. These elements were mainly related to abscisic acid (ABA) and methyl jasmonic acid (MEJA) stresses.

Additionally, the cis-elements responding to environmental stressors were attracted and identified in $B$. distachyon, including HSE [51], LTR, GC-motif and ARE [52], Box-W1, WUN-motif, and TC-rich [52]. Notably, GC-motif and ARE elements, involved in the regulation of gene expression in the absence of oxygen stress, were found to be abundant (1.000 and 1.474 copies). Development related elements, such as GCN4-motif, and CAT-box, were identified, which were relatively abundant (Additional file 1: Table S6) and associated with endosperm development and meristem growth, but their abundance did not differ significantly between monocotyledonous and dicotyledonous plants. Meanwhile, photoreactive element $S p 1$ is absent in the dicotyledonous Arabidopsis thaliana, but the abundance in $B$. distachyon (1.316 copy) is relatively high. This is similar to other monocotyledonous cereals, suggesting that $A R F$ genes may play a role in photosynthesis or carbohydrate synthesis.

Three-dimensional structure prediction of BdARF proteins and identification of critical amino acid sites

The three-dimensional structures of 19 BdARFs from $B$. distachyon were visually predicted by searching the
PHYRE2 database and using Pymol software [53]. All BdARF proteins had similar structural features; a representative BdARF1 is shown in Figure 4. Six key sites $(688 \mathrm{H}, 690 \mathrm{G}, 691 \mathrm{~L}, 774,839 \mathrm{G}$ and $856 \mathrm{~T})$ identified by positive selection and functional divergence are marked in green in the 3D structure (Fig. 4a and b). Three sites $(241 \mathrm{H}, 243 \mathrm{G}$ and $244 \mathrm{~L})$ were located on helix, two (340 T and $355 \mathrm{~T})$ on the loop and one $(310 \mathrm{~T})$ on the sheet. Interestingly, 5 sites $(241 \mathrm{H}, 243 \mathrm{G}, 244 \mathrm{~L}, 310 \mathrm{~T}$ and $355 \mathrm{~T})$ exist on the surface of the 3D structure (Fig. 4c and d).

\section{Protein interaction analysis of BdARFs}

The study of protein-protein interactions (PPI) facilitates understanding of gene function [54]. Therefore, to better understand whether ARF exerts biological functions through protein interaction, the STRING database was used to construct the PPI network for BdARFs [55]. The PPI networks and potential substrates were extracted from the whole interaction network and reconstructed using the software Cytoscape (version 3.0.2). A total of 10 BdARFs (none from clade II) and 5 Aux/IAA proteins were identified in the PPI network (Additional file 6: Figure S5).

\section{Expression of B. distachyon ARF genes in different tissues and organs}

The expression profiles of the $19 \mathrm{~B}$. distachyon ARF genes from different clades in six tissues and organs 


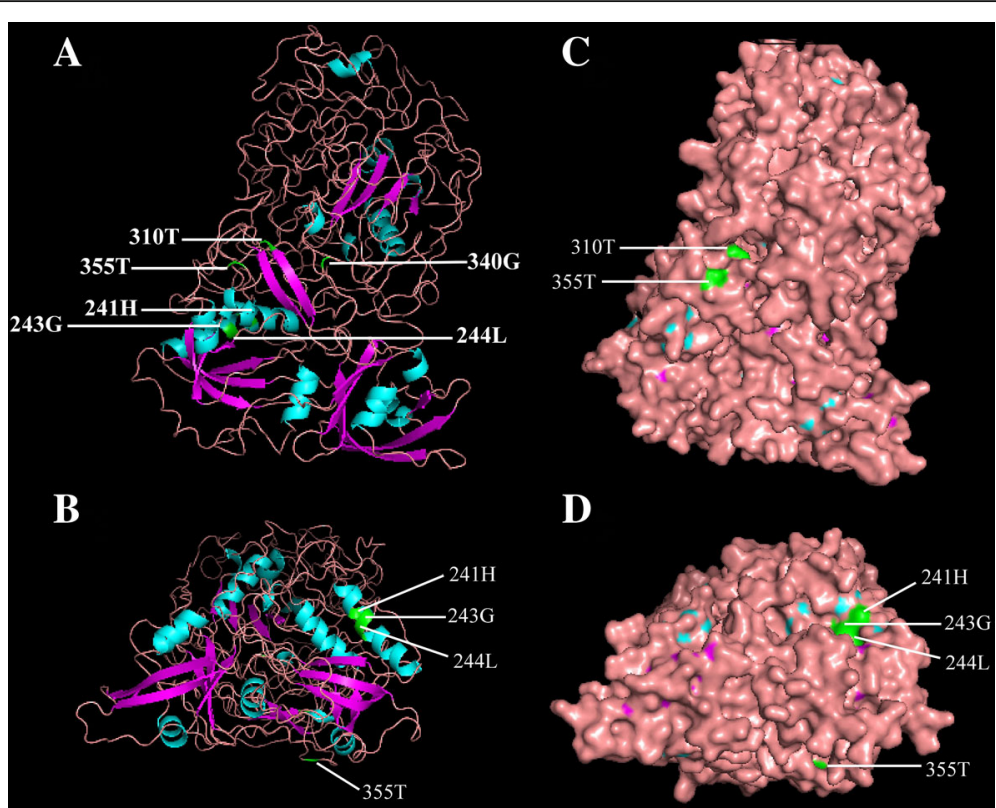

Fig. 4 Three-dimensional structure of $B$. distachyon ARF protein BdARF1. a. Schematic diagram of 3D structure of BdARF1. b Schematic diagram of 3D structure of BdARF1. It is obtained by (a) rotating 180 degrees clockwise and then 90 degrees upward. c Surface representation of BdARF1 corresponding to (a). d Surface representation of BdARF1 corresponding to (b). The precise positions of six critical amino acids were identified among Type I and Type II functional divergence and positive selection in the 3D structure. Five unique amino acid sites are shown on the surface of the 3D structure. In the figure, helix is represented by light blue, purple represents sheet, pink represents loop, and the six key amino acid positions are indicated by green. The amino acids represented by the six key positions and their positions in the protein sequence are labeled

were analyzed by qRT-PCR, including root, stem, leaf, root tip, leaf tip, and developing seeds at 15 days post-anthesis (DPA). The primer sequences for qRT-PCR assays are listed in Additional file 1: Table S7. The optimal parameters yielded a correlation coefficient $\left(\mathrm{r}^{2}\right)$ of $0.994-0.999$ and PCR amplification efficiency (E) of $90-110 \%$ (Additional file 7: Figure S6, Additional file 8: Figure S7).

As shown in Fig. 5, BdARFs generally had high expression levels in leaf and root tips, stems, and developing seeds. The $B d A R F$ genes from different clades also had expression differences. For clade I, BdARFs were mainly expressed in leaf and root tips or seeds. Six $B d A R F$ genes (BdARF6, BdARF7, BdARF8, BdARF9, BdARF10, and $B d A R F 14$ ) from clade Ia had high levels of expression in the leaf/root tips. Except for BdARF6 and BdARF8, the other four genes were also highly expressed in the seeds. This is consistent with the promoter analysis indicating that BdARF6 and BdARF8 have almost no cis-acting elements associated with endosperm development. The $B d A R F s$ from clade Ib also had similar expression preference. For example, BdARF1 was abundantly expressed in root tips, but was not expressed in roots and leaves. $B d A R F 5$ was expressed in all tissues and organs, except leaves, and its expression level was highest in developing seeds. BdARFs from clade II were mainly expressed in stem and leaf tips, of which BdARF11 and BdARF15 were mainly expressed in the stems, while BdARF12 and
$B d A R F 13$ were mainly expressed at the leaf tips. BdARFs from clade III were mainly expressed in the leaf and root tips and developing seeds, of which BdARF16 had an extremely high expression level in the seeds (Fig. 5).

\section{Expression profiling of $B$. distachyon ARFs in response to various abiotic stressors}

Nine representative $B d A R F s$ from the three clades were selected to further detect their expression patterns in both roots and leaves under different abiotic stressors (Fig. 6). These genes included BdARF6, BdARF8, and $B d A R F 10$ from clade Ia, $B d A R F 2$ and $B d A R F 4$ from clade Ib, BdARF12 and BdARF15 from clade II, and $B d A R F 17$ and BdARF18 from clade III. The abiotic stressors used were osmotic $(\mathrm{NaCl}$ and polyethylene glycol (PEG)), heat $\left(42^{\circ} \mathrm{C}\right)$, heavy metals $\left(\mathrm{Zn}^{2+}\right.$ and $\left.\mathrm{Cr}^{3+}\right)$, and phytohormones ABA, indole-3-acetic acid (IAA), and salicylic acid (SA). The primer sequences, optimal parameters, and PCR amplification efficiency are listed in Additional file 1: Table S7, Additional file 7: Figures S6 and Additional file 8: Figure S7, respectively.

In general, most of the nine $B d A R F s$ exhibited significantly upregulated expression in both roots and leaves in response to single and multiple abiotic stress treatments. Meanwhile, transcriptional expression differences were observed between $B d A R F$ members from different clades, including significant upregulation of $B d A R F 8$ 


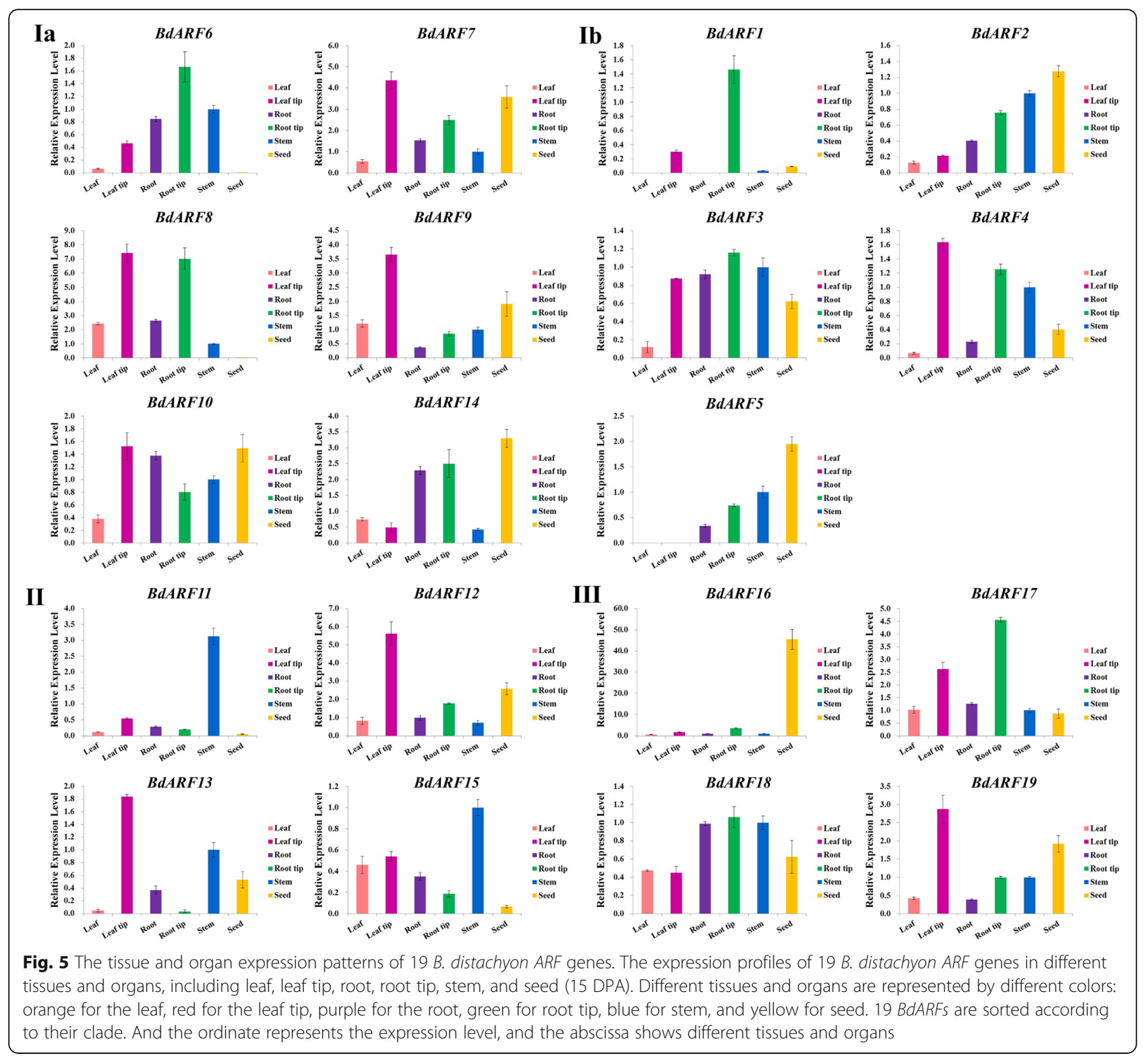

from clade Ia under IAA, SA, $\mathrm{Cr}^{3+}, \mathrm{Zn}^{2+}$, and PEG stressors; BdARF10 from the same clade under IAA stress; BdARF4 from clade $\mathrm{Ib}$ under $\mathrm{SA}, \mathrm{Cr}^{3+}$, and $\mathrm{Zn}^{2+}$ stressors; BdARF15 from clade II under IAA and SA stressors; and BdARF18 from clade III under ABA, $\mathrm{Zn}^{2+}$, and $\mathrm{NaCl}$ stressors (Fig. 6).

The BdARFs between roots and leaves also exhibited clear differences in expression under the abiotic stressors. In roots, almost all $B d A R F$ genes under IAA treatment were significantly upregulated, except for $B d A R F 2$ and BdARF12, which were significantly downregulated. In contrast, only $B d A R F 10$ and $B d A R F 18$ were upregulated and the others were downregulated under ABA treatment. The SA treatment significantly upregulated BdARF2, BdARF4, BdARF8, and BdARF15. Under heavy metal $\left(\mathrm{Zn}^{2+}\right.$ and $\left.\mathrm{Cr}^{3+}\right)$ stressors, BdARF4, $B d A R F 8$, and BdARF18 were significantly upregulated. When plants were suffering from osmotic stress, $B d A R F$ genes were more sensitive in roots than leaves, and generally exhibited significant downregulation after PEG and $\mathrm{NaCl}$ treatments. For heat stress, all genes were downregulated, except BdARF4 was significantly upregulated.

In leaves, $B d A R F s$ were generally significantly upregulated from hormone treatments, including all $B d A R F$ genes except BdARF2, BdARF17, and BdARF18 under IAA stress, four genes (BdARF6, BdARF4, BdARF17, and $B d A R F 18)$ under ABA stress, and five genes (BdARF4, BdARF8, BdARF12, BdARF15, and BdARF17) under SA stress. When subjected to heavy metal $\left(\mathrm{Zn}^{2+}\right.$ and $\left.\mathrm{Cr}^{3+}\right)$ 

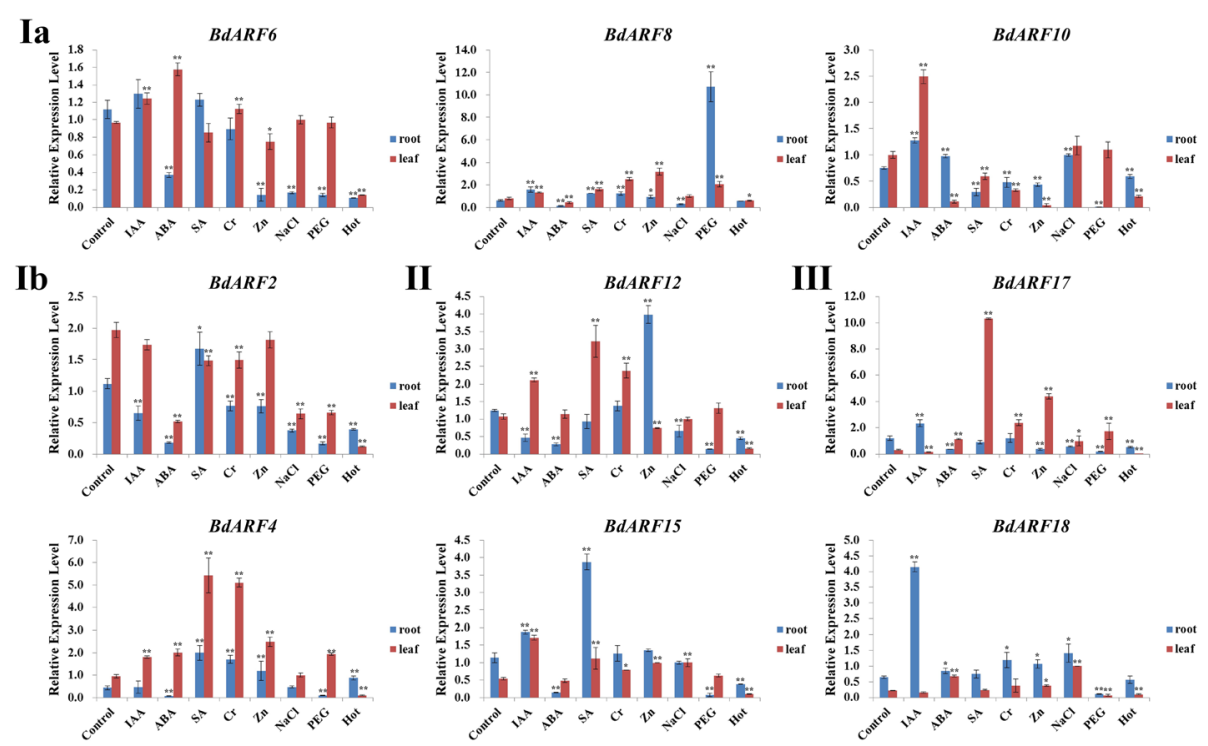

Fig. 6 Expression patterns of $B$. distachyon ARF genes under various abiotic stresses. The expression profiles of nine representative $B$. distachyon ARF genes under various abiotic stresses, including IAA, ABA, SA, $\mathrm{Cr}^{3+}, \mathrm{Zn}^{2+}, \mathrm{NaCl}, \mathrm{PEG}$ and Hot (42 $\left.{ }^{\circ} \mathrm{C}\right)$. IAA, indole-3-acetic acid; $\mathrm{ABA}$, abscisic acid; SA, salicylic acid; PEG, polyethylene glycol. The leaf and root are separately analyzed, red color bar presents leaf, sky blue color bar presents root. Statistically significant differences between control group and treatment group were calculated by an independent Student's $t$-tests: ${ }^{*} p<0.05$, ${ }^{* *} p<0.01 .9$ BdARFs are sorted according to their clade (Clade la: BdARF6, BdARF8, BdARF10; Clade Ib: BdARF2, BdARF4; Clade II: BdARF12, BdARF15; Clade III: BdARF17, BdARF18). And the ordinate represents the expression level, and the abscissa shows different tissues and organs

treatments, most of the nine $B d A R F s$ were upregulated, except two genes (BdARF2 and BdARF10) under $\mathrm{Cr}^{3+}$ stress and three genes (BdARF6, BdARF10 and $B d A R F 12)$ under $\mathrm{Zn}^{2+}$ stress were significantly downregulated. Under osmotic stress, BdARF15, BdARF17, and $B d A R F 18$ were significantly upregulated under $\mathrm{NaCl}$ stress and BdARF4, BdARF8, and BdARF17 were significantly upregulated under PEG stress. However, all
$B d A R F s$ were downregulated in response to heat stress (Fig. 6).

Our results revealed that five $B d A R F$ genes (BdARF4, $B d A R F 8, B d A R F 10, B d A R F 12$, and BdARF18) in roots and leaves generally displayed a significantly upregulated expression under $\mathrm{Cr}^{3+}, \mathrm{Zn}^{2+}$, PEG, and IAA treatments. Thus, the dynamic expression patterns of these BdARFs at six time points $(0,6,12,24$, and $48 \mathrm{~h}$, and recovery

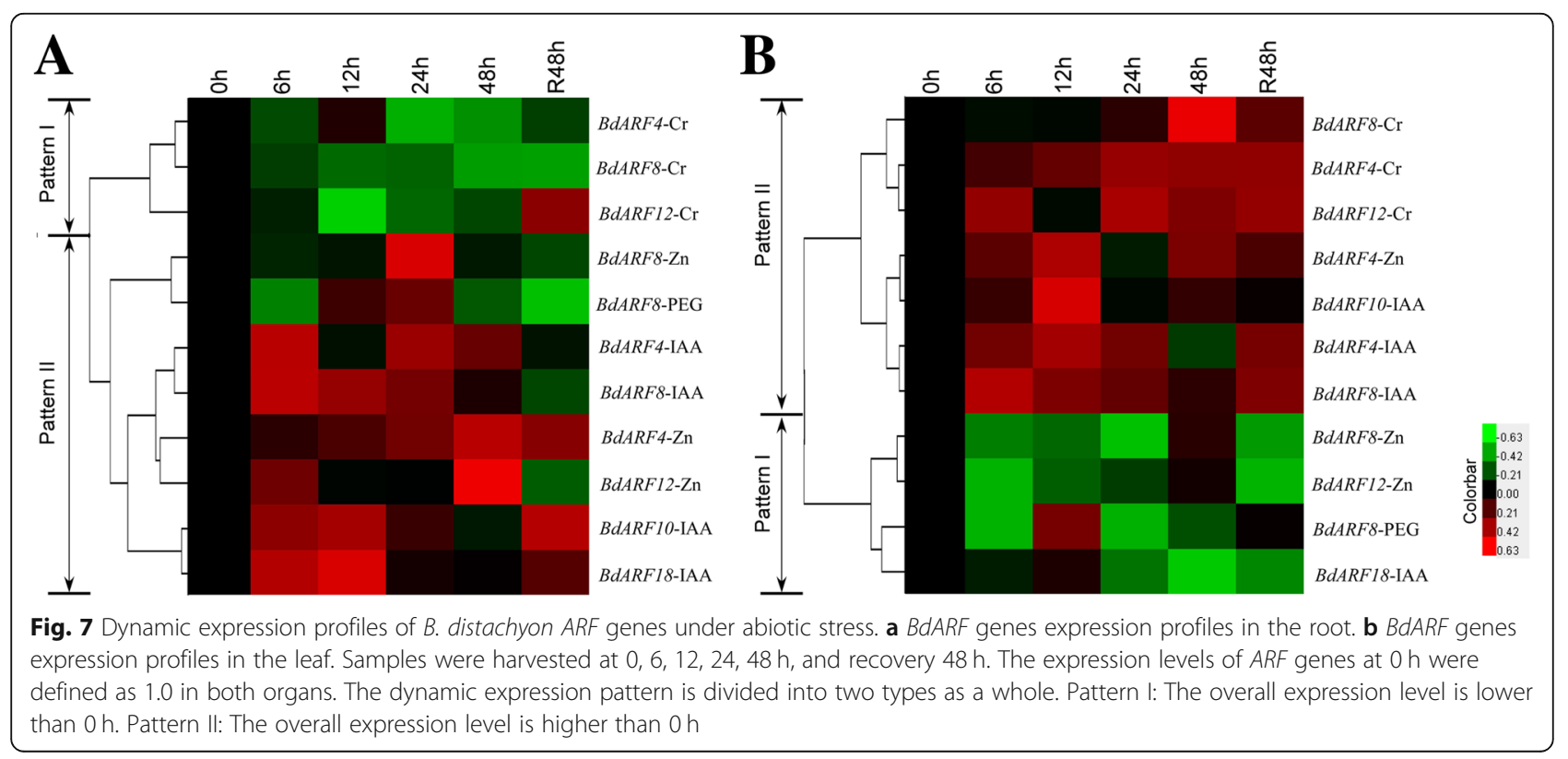


for $48 \mathrm{~h})$ under four stress treatments $\left(\mathrm{Cr}^{3+}, \mathrm{Zn}^{2+}, \mathrm{PEG}\right.$, and IAA) were further investigated (Fig. 7). The results revealed that $B d A R F s$ generally exhibited a distinct expression pattern of upregulation in leaves and downregulation in roots after stress treatments. Most BdARFs in roots were upregulated at 6,12 , and $24 \mathrm{~h}$ after treatments and downregulated at $48 \mathrm{~h}$ and after $48 \mathrm{~h}$ of recovery (Fig. 7a). In leaves, BdARFs were upregulated at $6,12,24$, and $48 \mathrm{~h}$ after stress treatments and at $48 \mathrm{~h}$ of recovery (Fig. $7 \mathrm{~b}$ ). Interestingly, the expression patterns of $B d A R F 4, B d A R F 8$, and BdARF12 were upregulated in both leaves and roots in response to IAA stress, but exhibited an opposite trend in roots (downregulation) and leaves (upregulation) under $\mathrm{Cr}^{3+}$ stress.

\section{Discussion}

Molecular characterization and evolution of the ARF gene family in B. distachyon

Genome-wide analysis indicated that 19 BdARFs from $B$. distachyon and 163 from six other plant species were divided into three clades (Fig. 3). The ARFs within a clade have similar intron-exon structure characteristics, suggesting the conservation of ARF structures within clades (Additional file 2: Figure S1). Most of the ARFs motifs are concentrated in 8-10 (Additional file 3: Figure S2 and Additional file 4: Figure S3), demonstrating the evolutionary conservation of ARFs among plant species. However, almost all of the clade II members lost two motifs, probably due to the influence of selection pressure in the evolutionary process. Further protein predictive analysis revealed that ARF can perform biological functions by forming homodimers or heterodimers, consistent with previous reports $[10,11,56]$. The clade II has no members involved in the protein interaction network (Additional file 6: Figure S5), possibly due to the lack of these two important motifs.

In a gene family, new genes produced by replication may either be retained due to the evolution of new functions, or they may be lost [57]. Generally, replicative genes are not under selective pressure in the early stages of evolution or do not exhibit the characteristics that usually appear under positive selection pressure. In the evolution of special functions, selection pressure tends to be negative because each gene has a fixed function [58, 59]. In this study, a site-specific model did not detect any positive selection sites (Additional file 1: Table S5), and the maize ARF gene family was found to be under negative selection [60]. Therefore, we speculate that the ancient plant ARF proteins have undergone negative selection to maintain their function.

Amino acid site mutations occur frequently and accumulate mass variations such that duplicate genes have diverged in function [61-64]. We found that functional disproportionation occurred between each pair of clades, and the number of Type II disproportionation sites was much greater than the Type I (Additional file 1: Table S4). The functional divergences between clades are mainly attributed to changes in the physicochemical properties of amino acids and changes in the rate of evolution [42]. Furthermore, 8 key amino acid sites have both Type I and Type II functional divergences. The evolutionary rate and physiochemical properties of these sites have changed, indicating that these sites are important for the functional differentiation of the ARF protein family. Particularly, six critical amino acid sites underwent both functional divergence and positive selection pressure, which could play key roles in the domain differentiation (Additional file 5: Figure S4).

\section{Expression and functions of $B$. distachyon ARFs in response to abiotic stressors}

Auxin plays an important role in the response to abiotic stressors, and ARF is an important transcription factor in the auxin signaling pathway [65]. The promoter region of the ARF contains a large number of cis-acting elements associated with abiotic stress, suggesting that $A R F$ may participate in stress defense.

The activity of ARFs is regulated by the concentration of auxin [8], so we focused on the effect of exogenous hormones on ARF expression. Almost all BdARFs were significantly upregulated in $B$. distachyon seedlings, roots, and leaves when subjected to IAA treatment. This phenomenon may be due to the fact that exogenous IAA affects the homeostasis of auxin and promotes the upregulation of transport inhibitor resistant 1 (TIR1), which has an F-box domain that binds to the SCF ubiquitin ligase to form the $\mathrm{SCF}^{\mathrm{TIR} 1}$ complex [66]. When Aux/IAA binds to the SCF ${ }^{\mathrm{TIR} 1}$ complex, it is ubiquitinated and subsequently degraded by the proteasome [4, 67]. Subsequently, ARF protein is released and accumulates due to the degradation of Aux/IAA, which activates or inhibits the expression of downstream genes [68]. As a critical plant hormone, ABA participates in the response to a wide range of abiotic stressors and regulates stress tolerance to cope with environmental stressors [69]. Plants can sense changes in the external environmental in a variety of ways, one of which is changes in auxin concentration [70]. When a stressor causes an increase in auxin, the plant activates ABA and other pathways [71], and promotes the expression of stress-defense genes, such as C-repeat/dehydration-responsive element-binding factors (CBFs) or responsive to dehydration (RDs) genes [72]. Meanwhile, a large number of GH3 family genes are induced by promoting the expression of ARF genes to negatively regulate auxin levels [72]. In the present study, we found that exogenous ABA and SA usually upregulated $B d A R F s$ in leaves (Fig. 6). Therefore, $B d A R F s$ could be induced by $\mathrm{ABA}$ and $\mathrm{SA}$, which 
activate the downstream genes to respond to phytohormone stress [15].

Heavy metal contamination is an increasingly serious global problem. An increase of reactive oxygen species (ROS) is a common phenomenon when plants are exposed to heavy metal stress [73, 74]. Along with increased ROS, plants cope with stress through the signaling pathway mediated by mitogen-activated protein kinase (MAPK) [75, 76]. The activated MAPK pathway may fight stress primarily by inducing the expression of some protective genes and activating the expression of repressive $\mathrm{ARFs}$ [77]. Additionally, ROS can influence the ubiquitin degradation pathway associated with ARF by inhibiting TIR1, further affecting endogenous auxin levels [70].

Under $\mathrm{NaCl}$ and PEG treatments, most $B d A R F$ s were inhibited, but $B d A R F 8, B d A R F 10$, and BdARF18 were significantly upregulated (Fig. 6), indicating that they are involved in osmotic stress response. A previous study found that SIARF8A and SIARF10A were upregulated in response to salt and drought stress in tomato plants [78]. Furthermore, AtARF8 in Arabidopsis may be involved in auxin homeostasis by affecting the growth habits of hypocotyls and roots [79]. AtARF10 influenced the formation of the root, implying it plays an important role in coping with stress [80]. Additionally, under salt and drought stress, plants activate GH3 through the expression of $A R F s$ and ABA pathway to maintain auxin homeostasis and activate relevant stress response genes to weaken or eliminate the effects of stress [72]. Our results suggest that only the BdARF4 gene was significantly upregulated in roots under heat stress. To date, the mechanism of plant $A R F s$ defense against heat stress is not clear. Numerous studies have found that ABA/SA and $\mathrm{Ca}^{2+}$, which represent ABA-dependent and calcium-dependent protein kinase (CDPK) signaling pathways, are involved in plant heat stress response [8183]. BdARF4 may participate in these signaling pathways to resist heat stress. Moreover, although plants maintain auxin homeostasis through an ARF-associated ubiquitin degradation pathway and an ABA pathway to cope with hormonal, osmotic, and heat stressors, the stress can also induce the accumulation of ROS and crosstalk with the ABA and other pathways to deal with complex abiotic stress [70, 84-86].

\section{Conclusions}

Genome-wide analysis identified 19 BdARFs in B. distachyon and 163 from six other plant species, which were divided into four clades. The intron-exon structure analysis revealed an evolutionarily conserved $A R F$ gene family. The functional divergence between clades was mainly attributed to changes in the physicochemical properties of amino acids, followed by changes in the rate of evolution. In particular, functional divergence and positive selection occurred simultaneously at six sites $(241 \mathrm{H}, 243 \mathrm{G}, 244 \mathrm{~L}, 310 \mathrm{~T}, 340 \mathrm{G}$ and $355 \mathrm{~T})$, suggesting their important roles in domain differentiation. BdARFs were located in the nucleus by subcellular localization prediction and empirical evidence. qRT-PCR analysis revealed that the expression of BdARFs had a tissue and organ expression preference, generally with high expression levels in leaf and root tips, stems, and developing seeds. Meanwhile, some BdARFs were significantly upregulated in response to abiotic stressors, indicating their involvement in stress resistance. Our results provide new evidence for further understanding the structure, evolution, and function of the plant $A R F$ gene family.

\section{Methods}

Genome-wide identification of $A R F$ genes in Brachypodium distachyon $\mathrm{L}$

$A R F$ genes from Brachypodium distachyon and other six plant species that represent plant lineages of monocots and dicots were identified, including Setaria italic, Oryza sativa, Sorghum bicolor, Zea mays, Triticum aestivum and Arabidopsis thaliana. ARF amino acid sequences from rice and Arabidopsis were acquired from the RGAP (http://rice.plantbiology.msu.edu/) and TAIR (http://www.arabidopsis.org/) databases, respectively. The possible ARFs in the respective plant species were retrieved in the plant database (http://www.phytozome.org; http:// wheat-urgi.versailles.inra.fr/Seq-Repository) [87] by BLASTP analysis using ARFs from rice and Arabidopsis as a query. All identified ARFs were further validated by a conserved domain search using SMART (http://smart.embl-heidelberg.de/) [35] and PFAM (http://pfam.xfam.org/) [36] databases, whose E values were less or equal to $1 \mathrm{E}-5$, consequently the redundant and partial sequences were removed manually.

\section{Chromosomal locations, subcellular localization and phylogenetic analysis}

The location of ARF genes on B. distachyon chromosomes obtained from Phytozome database was mapped by MapInspect program and manually modified.

The subcellular localization of ARFs was predicted according to the integration of prediction results of FUEL-mLoc Server (http://bioinfo.eie.polyu.edu.hk/ FUEL-mLoc/) [88], WoLF PSORT (http://www.genscript.com/wolf-psort.html) [89], CELLO version 2.5 (http://cello.life.nctu.edu.tw/) [90], Plant-mPLoc (http:// www.csbio.sjtu.edu.cn/bioinf/plant-multi/) [91] and UniProtKB (http://www.uniprot.org/). To verify the subcellular localization prediction, the full-length coding sequences of $A R F s$ without stop codon were cloned into the green fluorescent protein (GFP) vector to carry out 
subcellular localization. This recombined plasmid was transiently transformed into Arabidopsis mesophyll protoplasts by PEG-mediated transformation [92]. After an overnight incubation at $26^{\circ} \mathrm{C}$ in the dark, GFP signal was detected by a Zeiss LSM 780 fluorescence confocal microscopy.

Phylogenetic trees were constructed based on Bayesian inference using Markov Chain Monte Carlo (MCMC) method [39]. Multiple sequence alignment using full protein sequences were performed based on MUSCLE program (http://www.ebi.ac.uk/Tools/msa/muscle/) [37, 38].

\section{Protein properties and sequence analysis}

$\mathrm{pI} / \mathrm{MW}$ of ARFs was determined by the Compute $\mathrm{pI} /$ MW tool in ExPASy proteomics server database (http:// web.expasy.org/compute_pi/) [93]. The exon-intron structure of ARF genes was derived from the online Gene Structure Display Server v2.0 (GSDS: http:// gsds.cbi.pku.edu.cn) with coding sequences (CDS) and genomic sequences [40]. The MEME program (Multiple Em for Motif Elicitation v 4.10.2 (http://meme-suite.org/ tools/meme) [41] was employed to identify conserved motifs in the candidate ARF protein sequences. The MEME program was run locally and the parameters were set to a maximum of 10 motifs.

The 1500 bp upstream region of the ARF member region was used as the promoter distribution region, and the promoter sequence of the $A R F$ member was obtained from the Phytozome (www.phytozome.net) database. The resulting promoter sequences were submitted for promoter cis-element analysis in the PlantCARE database (http://bioinformatics.psb.ugent.be/webtools/ plantcare/html/) [46].

\section{Positive selection and functional divergence analyses}

This study used the maximum likelihood method to test positive selection, two models in the CODEML program in the PAML package [45, 94, 95]: site model and branch-site model were used to test whether members of the ARF protein family were positively selected during evolution. Using DIVERGE v2.0 software package combined with posterior probability analysis to analyze the function disproportionation of type I and type II between different subfamilies of the ARF family $[42,43,96]$.

\section{Three-dimensional structure visualization of BdARF protein}

The 3D structure of BdARF protein was constructed using the online software PHYRE2 (http://www.sbg.bio.ic.ac.uk/phyre2/html/page.cgi?id=index) [53]. Then, editing was performed by Pymol software (version 1.7.4 Schrödinger, LLC., http://pymol.org/) to visualize the three-dimensional structure of BdARF protein and to label the screened important amino acid sites on the 3D structure map.

\section{Prediction of ARFs interaction with related proteins}

The protein sequences of the ARFs were collected by BLAST analysis with the NCBI, which was used for PPI analysis by the Search Tool for the Retrieval of Interacting Genes/Proteins (STRING) database (version 9.1, http://string-db.org) [55]. Brachypodium distachyon L., a model plant for economically important crop species including wheat and barley was selected as organism, and the PPI network with a confidence score of at least 0.700 was constructed [97, 98] and displayed using Cytoscape (version 3.0.2) software [99].

\section{Plant seedling cultivation and abiotic stress treatments} Seeds of Bd21 were kindly provided by Dr. John Vogel from the U.S. Department of Agriculture (USDA) Agricultural Research Service (ARS). The uniform seeds of standard diploid inbred line $\mathrm{Bd} 21$ were sterilized with $75 \%$ alcohol and 15\% sodium hypochlorite, and then washed three times with sterile water. After sterilization, $500 \mathrm{~g}$ of seeds were germinated on water-filled filter paper for 3 days under complete darkness at $26^{\circ} \mathrm{C}$ in three biological replicates. At the fourth day, seedlings were transferred to dedicated cultivation baskets with full-strength Hoagland solution $\left(5 \mathrm{mM} \mathrm{KNO}_{3}, 5 \mathrm{mM}\right.$ $\mathrm{Ca}\left(\mathrm{NO}_{3}\right)_{2}, 2 \mathrm{mM} \quad \mathrm{MgSO}_{4}, \quad 1 \mathrm{mM} \quad \mathrm{KH}_{2} \mathrm{PO}_{4}, \quad 50 \mu \mathrm{M}$ $\mathrm{FeNa}_{2}(\text { EDTA) })_{2}, 50 \mu \mathrm{M} \mathrm{H} \mathrm{BO}_{3}, 10 \mu \mathrm{M} \mathrm{MnC1} 1_{2}, 0.8 \mu \mathrm{M}$ $\mathrm{ZnSO}_{4}, 0.4 \mu \mathrm{M} \mathrm{CuSO}$, and $\left.0.02 \mu \mathrm{M}\left(\mathrm{NH}_{4}\right)_{6} \mathrm{MoO}_{24}\right)$ in the greenhouse under a $16 / 8 \mathrm{~h}$ (light/dark) photocycle at $28 / 26^{\circ} \mathrm{C}$ (day/night) condition with relative humidity of $70 \%$. The nutrient solution was changed every 2-3 days. Five different organs and tissues (roots, stems, leaves, leaves tip and roots tip) were collected at three leaf stages in the control group as well as the developing seeds at 15 DPA. Meanwhile, seedlings were treated with the following conditions: salinity stress $(200 \mathrm{mM} \mathrm{NaCl})$, mild drought stress (20\% ( $w / v)$ PEG 6000), heavy metal stress $\left(300 \mu \mathrm{M} \quad \mathrm{CrCl}_{3}\right.$ and $\left.\mathrm{ZnSO}_{4}\right)$, hormone stress $\left(100 \mu \mathrm{M}\right.$ ABA and SA, $10 \mu \mathrm{M}$ IAA), hot stress $\left(42^{\circ} \mathrm{C}\right)$. Leaf and root samples of control seedlings were harvested at $0 \mathrm{~h}$. The samples from heat stress were collected at $2 \mathrm{~h}$, and those from other treated seedlings were harvested at $6,12,24,48 \mathrm{~h}$ and recover $48 \mathrm{~h}$. Each sample was collected from 10 plants with three biological replicates. All samples collected were immediately stored at $-80^{\circ} \mathrm{C}$ prior to use.

\section{Total mRNA extraction and analysis of genes expression levels of $B$. distachyon by qRT-PCR}

Total mRNA was extracted from the frozen samples collected using TRIzol Reagent (Invitrogen), and cDNA synthesis was performed using PrimeScript ${ }^{\bullet}$ RTReagent 
kit (TaKaRa, Shiga, Japan). All primers involved in the qRT-PCR process were designed using the online tool Primer3Plus (http://www.bioinformatics.nl/cgi-bin/primer3plus/primer3plus.cgi), and the specificity of the primers was examined by the corresponding dissociation curves and gel electrophoresis. Transcript levels were quantified using a CFX96 Real-Time PCR Detection System (Bio-Rad, Hercules, CA, USA) with the intercalating dye SYBR-green following the 2(-Delta Delta $\mathrm{C}(\mathrm{T})$ ) method [100]. Ubiquitin (Bradi3g20790) was used as the reference gene, and qRT-PCR was performed according to Cao et al. [101], and three biological replicates were performed on each sample and $\mathrm{Ct}$ values were averaged.

\section{Additional files}

Additional file 1: Table S1. The nomenclature, characteristics of ARF genes and their deduced proteins in seven representative plant species. Table S2. The parameters of conserved B3 and Auxin_resp domains from SMART and Pfam. Table S3 Sequences of primers for subcellular localization. Table S4. Amino acid sites of functional divergence between groups of ARFs subfamily. Table S5. Adaptive selection analysis of ARF genes using site-specific models. Table S6. cis-element analysis of $1500 \mathrm{bp}$ nucleotide sequences data upstream of the translation initiation codon of ARF genes. Table S7. Sequences of primers for qRT-PCR. (XLSX $262 \mathrm{~kb}$ )

Additional file 2: Figure S1. Exon-intron organization of ARF gene family. The bold yellow lines and gray lines represent exons and introns, respectively. The bold blue lines indicate the 5' upstream region (left) and the $3^{\prime}$ downstream region (right). All ARF genes are divided into four categories according to the clades. The members of each clade are sorted by species. (JPG $2 \mathrm{mb}$ )

Additional file 3: Figure S2. ARF proteins motifs schematic representation. The gray solid lines represent the corresponding ARF proteins and their length. The different-colored boxes represent different motifs and their position and order in individual ARF protein sequence. All ARF genes are divided into four categories according to clades and sorted according to the order of the phylogenetic tree. (JPG $2 \mathrm{mb}$ )

Additional file 4: Figure S3. Composition of ARF protein motifs. The order of motifs in the Schematic representation was automatically generated by MEME according to scores. The symbol heights represent the relative frequency of each residue. (JPG $3 \mathrm{mb}$ )

Additional file 5: Figure S4. Venn diagram of sites both in positive selection and functional divergence. In the Venn diagram, the green circle indicates the positive selection site, the yellow circle indicates the type I functional divergence site, and the blue circle indicates the type I| functional divergence site. The intersections represent the sites that occurd between the two or among the three. (JPG $1 \mathrm{mb}$ )

Additional file 6: Figure S5. Protein-protein interaction (PPI) network analysis of BdARF proteins. The figure shows the possible interactions between BdARFs and between BdARF and Aux/IAA family proteins. Red represents BdARF proteins with relatively close interactions, yellow represents BdARF proteins with a single interaction, and sky blue represents Aux/IAA family proteins (confidence score: 0.700). (JPG $711 \mathrm{~kb}$ )

Additional file 7: Figure S6. qRT-PCR double standard curves of BdARF genes. The red standard curves represent the reference gene (S-adenosylmethionine decarboxylase gene), the blue standard curves represent the target genes. The double standard curves of different genes are indicated. A to $S$ indicate $B d A R F 1$ to $B d A R F 19$ respectively. (JPG $3 \mathrm{mb}$ )

Additional file 8: Figure S7. qRT-PCR dissociation curves of BdARF genes. The red standard curves represent the reference gene (S-adenosylmethionine decarboxylase gene), the blue standard curves represent the target genes. The dissociation curves of different genes are indicated. A to $\mathrm{S}$ indicate $B d A R F 1$ to BdARF19 respectively. (JPG $2 \mathrm{mb}$ )

\section{Abbreviations}

ABA: Abscisic acid; AD: Activation domain; ARF: Auxin response factor; Aux/ IAA: Auxin/indole-3-acetic acid; AuxREs: Auxin response elements; CBF: Crepeat/dehydration-responsive element-binding factor; CDPK: Calcium Dependent Protein Kinase; CDS: Coding sequence; CTD: C-terminal dimerization domain; DAPI: 4',6-diamidino-2-phenylindole; DBD: DNA-binding domain; DPA: Days post-anthesis; GFP: Green fluorescent protein; IAA: Indole3-acetic acid; MAPK: Mitogen activated protein kinase; MAPKK: MAPK kinase; MAPKKK: MAPKK kinase; MCMC: Markov Chain Monte Carlo; MEME: Multiple Em for Motif Elicitation; MR: Middle transcriptional regulatory region; MUSCLE: Multiple Sequence Comparison by Log-Expectation; MW: Molecular weight; PEG: Polyethylene glycol; pl: Isoelectric point; PPI: Protein-protein interaction; qRT-PCR: Quantitative real-time polymerase chain reaction; RD: Repression domain; RDs: Response to dehydration genes; ROS: Reactive oxygen species; SA: Salicylic acid; TIR1: Transport Inhibitor Resistant 1

\section{Acknowledgements}

The English in this document has been checked by at least two professional editors, both native speakers of English. For a certificate, please see: http:// www.textcheck.com/certificate/BbLKxd.

\section{Funding}

This research was financially supported by grants from National Key R \& D Program of China (2016YFD0100502) and the National Natural Science Foundation of China (31771773). The funder has no role in the design of the study and collection, analysis, and interpretation of data and in writing the manuscript.

\section{Availability of data and materials}

All data generated or analysed during this study are included in this published article and its supplementary information files.

\section{Authors' contributions}

$L N$ and $D L$ carried out all experiments and data analysis. XD, LD and $Y L$ performed the preparation of RNA, CDNA, qRT-PCR and bioinformatics analyses. LM collected plant material, analyzed the results of bioinformatics and qRT-PCR and modified the manuscript. YY and HY conceived the study, planned experiments, and helped draft the manuscript. All authors read and approved the final manuscript.

Ethics approval and consent to participate

Not applicable.

\section{Consent for publication}

Not applicable.

\section{Competing interests}

The authors declare that they have no competing interests.

\section{Publisher's Note}

Springer Nature remains neutral with regard to jurisdictional claims in published maps and institutional affiliations.

Received: 7 June 2018 Accepted: 22 November 2018 Published online: 06 December 2018

\section{References}

1. Hagen G, Guilfoyle T. Auxin-responsive gene expression: genes, promoters and regulatory factors. Plant Mol Biol. 2002;49(3-4):373-85.

2. Abel S, Theologis A. Early genes and auxin action. Plant Physiol. 1996; 111(1):9.

3. Ghanashyam C, Jain M. Role of auxin-responsive genes in biotic stress responses. Plant Signal Behav. 2009;4(9):846-8.

4. Woodward AW, Bartel B. A receptor for auxin. Plant Cell. 2005;17(9):2425-9. 5. Quint M, Gray WM. Auxin signaling. Curr Opin Plant Biol. 2006;9(5):448-53.

6. Chandler JW. Auxin response factors. Plant Cell Environ. 2016;39(5):1014-28.

7. Ulmasov T, Hagen G, Guilfoyle TJ. Activation and repression of transcription by auxin-response factors. Proc Natl Acad Sci U S A. 1999;96(10):5844-9.

8. Tiwari SB, Hagen $G$, Guilfoyle T. The roles of auxin response factor domains in auxin-responsive transcription. Plant Cell. 2003;15(2):533-43. 
9. Guilfoyle TJ, Hagen G. Auxin response factors. Curr Opin Plant Biol. 2007; 10(5):453-60.

10. Kim J, Harter K, Theologis A. Protein-protein interactions among the aux/ IAA proteins. Proc Natl Acad Sci U S A. 1997;94(22):11786-91.

11. Guilfoyle TJ. The PB1 domain in auxin response factor and auX/IAA proteins: a versatile protein interaction module in the auxin response. Plant Cell. 2015;27(1):33-43.

12. Ulmasov T, Hagen G, Guilfoyle TJ. Dimerization and DNA binding of auxin response factors. Plant J. 1999;19(3):309-19.

13. Ulmasov T, Hagen G, Guilfoyle TJ. ARF1, a transcription factor that binds to auxin response elements. Science. 1997;276(5320):1865-8.

14. Okushima Y, Overvoorde PJ, Arima K, Alonso JM, Chan A, Chang C, Ecker JR, Hughes B, Lui A, Nguyen D, et al. Functional genomic analysis of the AUXIN RESPONSE FACTOR gene family members in Arabidopsis thaliana: unique and overlapping functions of ARF7 and ARF19. Plant Cell. 2005;17(2):444-63.

15. Wang D, Pei K, Fu Y, Sun Z, Li S, Liu H, Tang K, Han B, Tao Y. Genome-wide analysis of the auxin response factors (ARF) gene family in rice (Oryza sativa). Gene. 2007;394(1):13-24.

16. Xing H, Pudake RN, Guo G, Xing G, Hu Z, Zhang Y, Sun Q, Ni Z. Genomewide identification and expression profiling of auxin response factor (ARF) gene family in maize. BMC Genomics. 2011;12(1):178.

17. Ellis CM, Nagpal P, Young JC, Hagen G, Guilfoyle TJ, Reed JW. AUXIN RESPONSE FACTOR1 and AUXIN RESPONSE FACTOR2 regulate senescence and floral organ abscission in Arabidopsis thaliana. Development. 2005;132(20):4563-74.

18. Schruff MC, Spielman M, Tiwari S, Adams S, Fenby N, Scott RJ. The AUXIN RESPONSE FACTOR 2 gene of Arabidopsis links auxin signalling, cell division, and the size of seeds and other organs. Development. 2006;133(2):251-61.

19. Lim PO, Lee IC, Kim J, Kim HJ, Ryu JS, Woo HR, Nam HG. Auxin response factor 2 (ARF2) plays a major role in regulating auxin-mediated leaf longevity. J Exp Bot. 2010;61(5):1419-30.

20. Sessions A, Nemhauser JL, McColl A, Roe JL, Feldmann KA, Zambryski PC. ETTIN patterns the Arabidopsis floral meristem and reproductive organs. Develop. 1997;124(22):4481-91.

21. Hardtke CS, Berleth T. The Arabidopsis gene MONOPTEROS encodes a transcription factor mediating embryo axis formation and vascular development. EMBO J. 1998;17(5):1405-11.

22. Nagpal P, Ellis CM, Weber H, Ploense SE, Barkawi LS, Guilfoyle TJ, Hagen G, Alonso JM, Cohen JD, Farmer EE, et al. Auxin response factors ARF6 and ARF8 promote jasmonic acid production and flower maturation. Development. 2005;132(18):4107-18.

23. Okushima Y, Fukaki H, Onoda M, Theologis A, Tasaka M. ARF7 and ARF19 regulate lateral root formation via direct activation of $\angle B D / A S L$ genes in Arabidopsis. Plant Cell. 2007;19(1):118-30.

24. Kumar R, Tyagi AK, Sharma AK. Genome-wide analysis of auxin response factor (ARF) gene family from tomato and analysis of their role in flower and fruit development. Mol Gen Genomics. 2011;285(3):245-60.

25. Sagar M, Chervin C, Mila I, Hao Y, Roustan JP, Benichou M, Gibon Y, Biais B, Maury $P$, Latché $A$, et al. SI-ARF4, an auxin response factor involved in the control of sugar metabolism during tomato fruit development. Plant Physiol. 2013;161(3):1362-74.

26. Wang S, Zhang S, Sun C, Xu Y, Chen Y, Yu C, Qian Q, Jiang DA, Qi Y. Auxin response factor (OsARF12), a novel regulator for phosphate homeostasis in rice (Oryza sativa). New Phytol. 2014;201(1):91-103.

27. Jain M, Khurana JP. Transcript profiling reveals diverse roles of auxinresponsive genes during reproductive development and abiotic stress in rice. FEBS J. 2009;276(11):3148-62.

28. Wang S, Bai Y, Shen C, Wu Y, Zhang S, Jiang D, Guilfoyle TJ, Chen M, Qi Y. Auxin-related gene families in abiotic stress response in Sorghum bicolor. Funct Integr Genomic. 2010;10(4):533-46.

29. Van HC, Le DT, Nishiyama R, Watanabe YASUKO, Sulieman S, Tran UT, Tran LSP. The auxin response factor transcription factor family in soybean: genome-wide identification and expression analyses during development and water stress. DNA Res. 2013;20(5):511-24.

30. Hu W, Zuo J, Hou X, Yan Y, Wei Y, Liu J, Li M, Xu B, Jin Z. The auxin response factor gene family in banana: genome-wide identification and expression analyses during development, ripening, and abiotic stress. Front Plant Sci. 2015;6:742.

31. International Brachypodium Initiative. Genome sequencing and analysis of the model grass Brachypodium distachyon. Nature. 2010;463(7282):763-8.

32. Draper J, Mur LA, Jenkins G, Ghosh-Biswas GC, Bablak P, Hasterok R, Routledge AP. Brachypodium distachyon. A new model system for functional genomics in grasses. Plant Physiol. 2001;127(4):1539-55.
33. Vogel J, Hill T. High-efficiency Agrobacterium-mediated transformation of Brachypodium distachyon inbred line Bd21-3. Plant Cell Rep. 2008: 27(3):471-8.

34. Opanowicz M, Vain P, Draper J, Parker D, Doonan JH. Brachypodium distachyon: making hay with a wild grass. Trends Plant Sci. 2008;13(4):172-7.

35. Letunic I, Doerks T, Bork P. SMART: recent updates, new developments and status in 2015. Nucleic Acids Res. 2014;43(D1):D257-60.

36. Finn RD, Coggill P, Eberhardt RY, Eddy SR, Mistry J, Mitchell AL, Potter SC, Punta M, Qureshi M, Sangrador-Vegas A, et al. The Pfam protein families database: towards a more sustainable future. Nucleic Acids Res. 2015;44(D1): D279-85.

37. Edgar RC. MUSCLE: a multiple sequence alignment method with reduced time and space complexity. BMC Bioinformatics. 2004;5(1):113.

38. Edgar RC. MUSCLE: multiple sequence alignment with high accuracy and high throughput. Nucleic Acids Res. 2004;32(5):1792-7.

39. Hall BG. Comparison of the accuracies of several phylogenetic methods using protein and DNA sequences. Mol Biol Evol. 2004;22(3):792-802.

40. Hu B, Jin J, Guo AY, Zhang H, Luo J, Gao G. GSDS 2.0: an upgraded gene feature visualization server. Bioinformatics. 2014;31(8):1296-7.

41. Bailey TL, Boden M, Buske FA, Frith M, Grant CE, Clementi L, Ren J, Li WW, Noble WS. MEME SUITE: tools for motif discovery and searching. Nucleic Acids Res. 2009;37:W202-8.

42. Gaucher EA, Gu X, Miyamoto MM, Benner SA. Predicting functional divergence in protein evolution by site-specific rate shifts. Trends Biochem Sci. 2002;27(6):315-21.

43. Gu X. A simple statistical method for estimating type-II (cluster-specific) functional divergence of protein sequences. Mol Biol Evol. 2006;23(10):1937-45.

44. Yang Z, Wong WS, Nielsen R. Bayes empirical Bayes inference of amino acid sites under positive selection. Mol Biol Evol. 2005;22(4):1107-18.

45. Anisimova M, Bielawski JP, Yang Z. Accuracy and power of Bayes prediction of amino acid sites under positive selection. Mol Biol Evol. 2002;19(6):950-8.

46. Lescot M, Déhais $P$, Thiijs $G$, Marchal $K$, Moreau $Y$, Van de PY, Rouzé $P$, Rombauts S. PlantCARE, a database of plant cis-acting regulatory elements and a portal to tools for in silico analysis of promoter sequences. Nucleic Acids Res. 2002;30(1):325-7.

47. Kim JK, Cao J, Wu R. Regulation and interaction of multiple protein factors with the proximal promoter regions of a rice high pl a-amylase gene. Mol Gen Genet. 1992;232(3):383-93.

48. Ogawa M, Hanada A, Yamauchi Y, Kuwahara A, Kamiya Y, Yamaguchi S. Gibberellin biosynthesis and response during Arabidopsis seed germination. Plant Cell. 2003;15(7):1591-604.

49. Pastuglia M, Roby D, Dumas C, Cock JM. Rapid induction by wounding and bacterial infection of an $S$ gene family receptor-like kinase gene in Brassica oleracea. Plant Cell. 1997;9(1):49-60.

50. Simpson SD, Nakashima K, Narusaka Y, Seki M, Shinozaki K, YamaguchiShinozak K. Two different novel cis-acting elements of erd1, a clpA homologous Arabidopsis gene function in induction by dehydration stress and dark-induced senescence. Plant J. 2003;33(2):259-70.

51. Freitas FZ, Bertolini MC. Genomic organization of the Neurospora crassa gsn gene: possible involvement of the STRE and HSE elements in the modulation of transcription during heat shock. Mol Gen Genomics. 2004; 272(5):550-61.

52. Klotz KL, Lagrimini LM. Phytohormone control of the tobacco anionic peroxidase promoter. Plant Mol Biol. 1996;31(3):565-73.

53. Kelley LA, Sternberg MJ. Protein structure prediction on the web: a case study using the Phyre server. Nat Protoc. 2009;4(3):363-71.

54. Tohge T, Fernie AR. Combining genetic diversity, informatics and metabolomics to facilitate annotation of plant gene function. Nat Protoc. 2010:5(6):1210-27.

55. Szklarczyk D, Franceschini A, Kuhn M, Simonovic M, Roth A, Minguez P, Doerks T, Stark M, Muller J, Bork P, et al. The STRING database in 2011: functional interaction networks of proteins, globally integrated and scored. Nucleic Acids Res. 2010;39:D561-8.

56. Guilfoyle TJ, Hagen G. Getting a grasp on domain III/V responsible for auxin response factor-IAA protein interactions. Plant Sci. 2012;190(3):82-8.

57. Lynch M, Conery JS. The evolutionary fate and consequences of duplicate genes. Science. 2000;290(5494):1151-5.

58. Kondrashov FA, Rogozin IB, Wolf YI, Koonin EV. Selection in the evolution of gene duplications. Genome Biol. 2002;3(2):1-9.

59. Zhang J, Dean AM, Brunet F, Long M. Evolving protein functional diversity in new genes of Drosophila. Proc Natl Acad Sci U S A. 2004;101(46):16246-50. 
60. Wang Y, Deng D, Shi Y, Miao N, Bian Y, Yin Z. Diversification, phylogeny and evolution of auxin response factor (ARF) family: insights gained from analyzing maize ARF genes. Mol Biol Rep. 2012;39(3):2401-15.

61. Blanc G, Wolfe KH. Widespread paleopolyploidy in model plant species inferred from age distributions of duplicate genes. Plant Cell. 2004;16(7):1667-78.

62. Gu X, Zhang Z, Huang W. Rapid evolution of expression and regulatory divergences after yeast gene duplication. Proc Natl Acad Sci U S A. 2005; 102(3):707-12.

63. Semon M, Wolfe $\mathrm{KH}$. Consequences of genome duplication. Curr Opin Genet Dev. 2007;17(6):505-12.

64. Ha M, Kim ED, Chen ZJ. Duplicate genes increase expression diversity in closely related species and allopolyploids. Proc Natl Acad Sci U S A. 2009; 106(7):2295-300

65. Shibasaki K, Uemura M, Tsurumi S, Rahman A. Auxin response in Arabidopsis under cold stress: underlying molecular mechanisms. Plant Cell. 2009;21(12): 3823-38.

66. Lee DJ, Park JW, Lee HW, Kim J. Genome-wide analysis of the auxinresponsive transcriptome downstream of iaal and its expression analysis reveal the diversity and complexity of auxin-regulated gene expression. J Exp Bot. 2009;60(13):3935-57.

67. Salehin M, Bagchi R, Estelle M. SCF ${ }^{\text {TIR1/AFB }}$-based auxin perception: mechanism and role in plant growth and development. Plant Cell. 2015;27(1):9-19.

68. Jain M, Nijhawan A, Arora R, Agarwal P, Ray S, Sharma P, Kapoor S, Tyagi AK, Khurana JP. F-box proteins in rice. Genome-wide analysis, classification, temporal and spatial gene expression during panicle and seed development, and regulation by light and abiotic stress. Plant Physiol. 2007; 143(4):1467-83.

69. Raghavendra AS, Gonugunta VK, Christmann A, Grill E. ABA perception and signalling. Trends Plant Sci. 2010;15(7):395-401.

70. Park CM. Auxin homeostasis in plant stress adaptation response. Plant Signal Behav. 2007;2(4):306-7.

71. Rock CD, Sun X. Crosstalk between ABA and auxin signaling pathways in roots of Arabidopsis thaliana (L.) Heynh. Planta. 2005;222(1):98-106.

72. Park JE, Park JY, Kim YS, Staswick PE, Jeon J, Yun J, Kim SY, Kim J, Lee $\mathrm{YH}$, Park CM. GH3-mediated auxin homeostasis links growth regulation with stress adaptation response in Arabidopsis. J Biol Chem. 2007; 282(13):10036-46.

73. Shahid M, Pourrut B, Dumat C, Nadeem M, Aslam M, Pinelli E. Heavy-metalinduced reactive oxygen species: phytotoxicity and physicochemical changes in plants. Rev Environ Contam T. 2014;232:1-44.

74. Yuan HM, Liu WC, Jin Y, Lu YT. Role of ROS and auxin in plant response to metal-mediated stress. Plant Signal Behav. 2013;8(7):e24671.

75. Kovtun Y, Chiu WL, Tena G, Sheen J. Functional analysis of oxidative stressactivated mitogen-activated protein kinase cascade in plants. Proc Natl Acad Sci U S A. 2000;97(6):2940-5.

76. Seger R, Krebs EG. The MAPK signaling cascade. FASEB J. 1995;9(9):726-35.

77. Danquah A, Zelicourt A, Colcombet J, Hirt H. The role of ABA and MAPK signaling pathways in plant abiotic stress responses. Biotechnol Adv. 2014; 32(1):40-52.

78. Bouzroud S, Gouiaa S, Hu N, Bernadac A, Mila I, Bendaou N, Smouni A, Bouzayen M, Zouine M. Auxin response factors (ARFs) are potential mediators of auxin action in tomato response to biotic and abiotic stress (Solanum lycopersicum). PLoS One. 2018;13(2):e0193517.

79. Tian CE, Muto H, Higuchi K, Matamura T, Tatematsu K, Koshiba T, Yamamoto KT. Disruption and overexpression of auxin response factor 8 gene of Arabidopsis affect hypocotyl elongation and root growth habit, indicating its possible involvement in auxin homeostasis in light condition. Plant J. 2004; 40(3):333-43.

80. Wang JW, Wang L, Mao YB, Cai WJ, Xue HW, Chen XY. Control of root cap formation by microRNA-targeted auxin response factors in Arabidopsis. Plant Cell. 2005;17(8):2204-16.

81. Mosser DD, Kotzbauer PT, Sarge KD, Morimoto RI. In vitro activation of heat shock transcription factor DNA-binding by calcium and biochemical conditions that affect protein conformation. Proc Natl Acad Sci U S A. 1990; 87(10):3748-52.

82. Talanova W, Titov AF. Endogenous abscisic acid content in cucumber leaves under the influence of unfavourable temperatures and salinity. J Exp Bot. 1994:45(7):1031-3.

83. Lopez-Delgado H, Dat JF, Foyer $\mathrm{CH}$, Scott IM. Induction of thermotolerance in potato microplants by acetylsalicylic acid and $\mathrm{H}_{2} \mathrm{O}_{2}$. J Exp Bot. 1998; 49(321):713-20.
84. Tognetti VB, Mühlenbock PER, Van Breusegem F. Stress homeostasis-the redox and auxin perspective. Plant Cell Environ. 2012;35(2):321-33.

85. Paponov IA, Paponov M, Teale W, Menges M, Chakrabortee S, Murray JA, Palme K. Comprehensive transcriptome analysis of auxin responses in Arabidopsis. Mol Plant. 2008;1(2):321-37.

86. Suzuki N, Koussevitzky S, Mittler RON, Miller GAD. ROS and redox signalling in the response of plants to abiotic stress. Plant Cell Environ. 2012;35(2):259-70.

87. Appels R, Eversole K, Feuillet C, Keller B, Rogers J, Stein N, Ronen G, et al. Shifting the limits in wheat research and breeding using a fully annotated reference genome. Science. 2018;361:6403.

88. Wan S, Mak MW, Kung SY. FUEL-mLoc: feature-unified prediction and explanation of multi-localization of cellular proteins in multiple organisms. Bioinformatics. 2016;33(5):749-50.

89. Horton P, Park KJ, Obayashi T, Nakai K. Protein subcellular localization prediction with WoLF PSORT. Proceedings of the 4th Annual Asia Pacific Bioinformatics Conference APBC06. 2006. pp. 39-48.

90. Yu CS, Lin CJ, Hwang JK. Predicting subcellular localization of proteins for gram-negative bacteria by support vector machines based on n-peptide compositions. Protein Sci. 2004;13(5):1402-6.

91. Chou KC, Shen HB. Plant-mPLoc: a top-down strategy to augment the power for predicting plant protein subcellular localization. PLoS One. 2010; 5(6):e11335

92. Yoo SD, Cho YH, Sheen J. Arabidopsis mesophyll protoplasts: a versatile cell system for transient gene expression analysis. Nat Protoc. 2007;2(7):1565.

93. Bjellqvist B, Basse B, Olsen E, Celis JE. Reference points for comparisons of two-dimensional maps of proteins from different human cell types defined in a $\mathrm{pH}$ scale where isoelectric points correlate with polypeptide compositions. Electrophoresis. 1994;15(1):529-39.

94. Wong WS, Yang Z, Goldman N, Nielsen R. Accuracy and power of statistical methods for detecting adaptive evolution in protein coding sequences and for identifying positively selected sites. Genetics. 2004;168(2):1041-51.

95. Yang Z. PAML 4: phylogenetic analysis by maximum likelihood. Mol Biol Evol. 2007;24(8):1586-91

96. Gu X. Statistical methods for testing functional divergence after gene duplication. Mol Biol Evol. 1999;16(12):1664-74.

97. Suo J, Zhao Q, Zhang Z, Chen S, Cao J, Liu G, Wei X, Wang T, Yang C, Dai S. Cytological and proteomic analyses of Osmunda cinnamomea germinating spores reveal characteristics of fern spore germination and rhizoid tip growth. Mol Cell Proteomics. 2015;14(9):2510-34.

98. Zhao Q, Gao J, Suo J, Chen S, Wang T, Dai S. Cytological and proteomic analyses of horsetail (Equisetum arvense L.) spore germination. Front Plant Sci. 2015:6:441.

99. Shannon P, Markiel A, Ozier O, Baliga NS, Wang JT, Ramage D, Amin N, Schwikowski B, Ideker T. Cytoscape: a software environment for integrated models of biomolecular interaction networks. Genome Res. 2003;13(11): 2498-504.

100. Livak KJ, Schmittgen TD. Analysis of relative gene expression data using real-time quantitative PCR and the $2-\Delta \Delta C T$ method. Methods. 2001;25(4): 402-8.

101. Cao H, Xu Y, Yuan L, Bian Y, Wang L, Zhen S, Hu Y, Yan Y. Molecular characterization of the 14-3-3 gene family in Brachypodium distachyon $\mathrm{L}$. reveals high evolutionary conservation and diverse responses to abiotic stresses. Front Plant Sci. 2016;7:1099.

Ready to submit your research? Choose BMC and benefit from:

- fast, convenient online submission

- thorough peer review by experienced researchers in your field

- rapid publication on acceptance

- support for research data, including large and complex data types

- gold Open Access which fosters wider collaboration and increased citations

- maximum visibility for your research: over $100 \mathrm{M}$ website views per year

At $\mathrm{BMC}$, research is always in progress.

Learn more biomedcentral.com/submissions 